\title{
Computational Technique
}

National Cancer Institute

\section{Source}

National Cancer Institute. Computational Technique. NCI Thesaurus. Code C19233.

The utilization or development of computer programs to solve, analyze, understand or manage any simple or complex task. 